FORMATION Formation emploi

Revue française de sciences sociales

106 | avril-juin 2009

Pêle-mêle

\title{
Avancer dans les analyses pour mieux orienter l'action
}

Jean-Frédéric Vergnies

\section{(2) OpenEdition}

1 Journals

Édition électronique

URL : http://journals.openedition.org/formationemploi/1882

DOI : 10.4000/formationemploi.1882

ISSN : 2107-0946

Éditeur

La Documentation française

Édition imprimée

Date de publication : 1 juin 2009

Pagination : 1

ISSN : 0759-6340

\section{Référence électronique}

Jean-Frédéric Vergnies, « Avancer dans les analyses pour mieux orienter l'action », Formation emploi

[En ligne], 106 | avril-juin 2009, mis en ligne le 18 novembre 2009, consulté le 30 octobre 2020. URL : http://journals.openedition.org/formationemploi/1882 ; DOI : https://doi.org/10.4000/

formationemploi.1882

(c) Tous droits réservés 


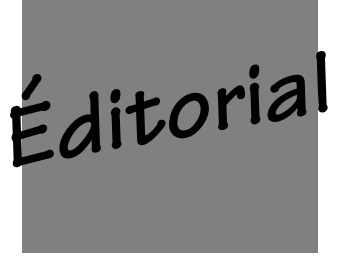

\section{Avancer dans les analyses pour mieux orienter l'action}

es analyses de la relation formation-travail-emploi privilégient volontiers des approches en termes de diplômes. Les conditions d'insertion après tel ou tel diplôme deviennent ainsi des indicateurs de performance de plus en plus sollicités. Pourtant, selon Catherine Béduwé, Bernard Fourcade et Jean-François Giret, pour les diplômés de l'université, le parcours de formation antérieur au diplôme final peut être aussi déterminant sur le marché du travail que le diplôme final lui-même.

Un autre point souvent débattu est la tranversalité ou la spécialisation des formations. Selon Emmanuel Quenson, même lorsque les représentants des entreprises et de l'Éducation nationale sont initialement d'accord pour instaurer un diplôme transversal (ici un bac pro de la production), au final, la réalité du marché du travail et l'organisation du travail sont plus complexes et variables que prévu, et les conditions d'insertion des jeunes titulaires de ce bac pro d'autant plus délicates.

L'accent mis sur l'organisation du travail et les conditions de travail se retrouve dans les analyses de Franck Bailly, Alexandre Léné et Marie-Hélène Toutin. Ils étudient la portée des périodes de formation en entreprise (stages, alternance) et leurs éventuelles conséquences en termes d'expérience professionnelle. En effet, dans le secteur des services, les conditions de travail et les représentations des employeurs jouent un rôle déterminant dans la possible valeur formatrice des stages.

En interrogeant la place de l'écrit au travail, Frédéric Moatty et Françoise Rouard étendent l'analyse à l'ensemble des emplois. Ici aussi il ressort qu'au-delà de la question du contenu des formations (lecture ou écriture) ou du niveau de formation des salariés, les compétences langagières des salariés reposent sur les conditions de travail.

À leur manière, Philippe Trouvé et Paul Santelmann examinent aussi les rapports entre l'organisation productive, l'évolution des qualifications professionnelles et celle des diplômes mis en place par le système éducatif. Ils poursuivent la réflexion initiée par Paul Santelmann dans le numéro 105, pour débattre des distorsions entre formation et emploi, entre diplômes et qualifications.

Bonne lecture. 